\title{
Surgical site infection and its association with rupture of membrane following cesarean section in Africa: a systematic review and meta-analysis of published studies
}

\author{
Alemayehu Gonie Mekonnen ${ }^{*^{*}}$ (i) and Yohannes Moges Mittiku²
}

\begin{abstract}
Introduction: Surgical site infection occurs within 30 days after a surgical procedure and involves the skin, subcutaneous tissue, and soft tissue. Surgical site infection following cesarean section is a common postoperative complication and is associated with maternal morbidity and mortality in resource-limited settings. Even though the proportion of surgical site infection and some risk factors were reported by kinds of literature, varying results were stated across studies. There is also limited knowledge on the association between postpartum surgical site infection and the rupture of membrane. Hence, this systematic review and meta-analysis was designed to estimate the pooled proportion of surgical site infection and its association with rupture of membrane following cesarean section in Africa.
\end{abstract}

Methods: Studies published from January 01, 2000 to January 30, 2020 were searched from MEDLINE via PubMed, Scopus, Medscape, Web-science and CINAHL databases to search relevant published articles. We also performed a manual search of reference lists of key articles to retrieve additional relevant articles. Initially, 559 records were identified and 15 studies included in the analysis. The statistical analysis was performed using STATA 11. Heterogeneity between-study was explored by forest plot and inconsistency index $\left(I^{2}\right)$. The publication bias was checked by a funnel plot and Egger's test. Pooled estimates of proportion and odds ratio were calculated by a random-effects model with a 95\% confidence interval (Cl).

Results: The overall pooled proportion of surgical site infection following cesarean section was $10.21 \%\left(1^{2}=86.8\right.$, $p<0.000 ; 95 \% \mathrm{Cl}=8.36,12.06)$. The odds of developing surgical site infection among women who had the rupture of membrane before delivery were nearly 6 times higher than those who had not a rupture of the membrane $(\mathrm{AOR}=5.65,95 \% \mathrm{Cl}: 3.95-8.07)$.

* Correspondence: alemayehugonie19@gmail.com

'Department of Nursing, College of Health Science, Debre Berhan University, Po. Box. 445, Debre Berhan, Ethiopia

Full list of author information is available at the end of the article

C C The Author(s). 2021 Open Access This article is licensed under a Creative Commons Attribution 4.0 International License, which permits use, sharing, adaptation, distribution and reproduction in any medium or format, as long as you give appropriate credit to the original author(s) and the source, provide a link to the Creative Commons licence, and indicate if changes were made. The images or other third party material in this article are included in the article's Creative Commons licence, unless indicated otherwise in a credit line to the material. If material is not included in the article's Creative Commons licence and your intended use is not permitted by statutory regulation or exceeds the permitted use, you will need to obtain permission directly from the copyright holder. To view a copy of this licence, visit http://creativecommons.org/licenses/by/4.0/ The Creative Commons Public Domain Dedication waiver (http://creativecommons.org/publicdomain/zero/1.0/) applies to the data made available in this article, unless otherwise stated in a credit line to the data. 
(Continued from previous page)

Conclusions: The proportion of surgical site infections following the cesarean section is relatively high. Women who had rupture of the membrane before delivery were more likely to develop surgical site infections following the cesarean section. Due attention should be given to the provision of prophylactic antibiotics that can reduce surgical site infection after cesarean delivery.

Keywords: Surgical site infection, Rupture of the membrane, Cesarean section, Meta-analysis

\section{Introduction}

Cesarean section (CS) is a surgical procedure where a baby is delivered by cutting through the front wall of the abdomen to open the uterus [1]. CS is often performed in an emergency situation and saves millions of lives worldwide [2, 3]. Globally, the proportion of CS is approximately $15 \%$ of all deliveries [4] and the rates are continuing to increase making the burden of surgical site infection an increasingly important issue [5]. As with all surgical procedures, CS can be associated with higher maternal morbidity and mortality during the postpartum period $[2,5]$.

Surgical site infection (SSI) is defined as an infection that occurs within 30 days after a surgical procedure involving the skin, subcutaneous tissue, and soft tissue $[1,2]$. Surgical site infection following CS is a common postoperative complication and is associated with maternal morbidity and mortality specifically in resourcelimited settings [6, 7]. It is the foremost predisposing factor for the widespread aversion to the CS in developing countries particularly in Africa $[8,9]$.

Surgical site infection following CS range from 3 to $15 \%$ worldwide [10]. In Africa, the incidence of SSI ranges from $5 \%$ in Tunisia [11] to $16.7 \%$ in Egypt [12]. The incidence of SSI is usually taken as an indicator of surgical quality [13]. Patients who develop SSIs were five times more likely to be readmitted to hospital and two times more likely to die compared with patients without SSIs [14]. As such, postpartum surgical site infection is a major cause of prolonged hospital stay and poses a burden to the health care system and it also increases an additional costs to mothers and their families $[3,10]$.

In order to control and prevent post-cesarean wound infection, strict preventative strategies and surgical site infection surveillance systems must be implemented [8]. Previous studies have shown that certain interventions lower SSIs [12]. The world health organization and other studies indicated that quantifying the magnitude of SSIs rate and associated factors can decrease up to $50 \%$ of surgical site infections $[15,16]$. Furthermore, lower rates of SSIs have been found with preoperative administration of the first-generation antibiotic and by improving the operative room practices [14].

Despite improvements in operating room practices, instrument sterilization methods and better surgical technique, surgical site infections remain a major cause of hospital-acquired infections and rates have been reached their highest levels even in hospitals with most modern facilities [14]. As reported by substantial body of research evidence, patient characteristics and perioperative management were found to be the risk factors for developing SSIs [12-14]. Even though the proportion of surgical site infection and some risk factors were reported by kinds of literature, varying results were stated across studies. There is also limited knowledge on the association between postpartum surgical site infection and the rupture of membrane, especially in developing countries. Therefore, the aim of this systematic review and meta-analysis was designed to estimate the pooled proportion of surgical site infection and its association with rupture of membrane following cesarean section which is currently unknown in Africa.

\section{Hypothesis/review question}

The overarching research question was: what is the best available evidence on the proportion of surgical site infection and its association with rupture of the membrane (ROM) following CS in Africa?

\section{Methods}

This systematic review and meta-analysis is reported in accordance with the meta-analysis of observational studies in epidemiology guidelines [17]. The search strategy focused on studies published from January 01, 2000 to January 30, 2020. The review authors used MEDLINE via PubMed, Scopus, Medscape, Web-science and CINA HL (Cumulative Index to Nursing and Allied Health Literature) databases to search relevant published articles. The search terms were: Infections, Surgical Wound OR Surgical Wound Infections OR Wound Infections, Surgical OR Infection, Surgical Wound OR Surgical Site Infection OR Infection, Surgical Site OR Infections, Surgical Site OR Surgical Site Infections OR Wound Infection, Postoperative OR Wound Infection, Surgical OR Infection, Postoperative Wound OR Infections, Postoperative Wound OR Postoperative Wound Infections OR Wound Infections, Postoperative OR Postoperative Wound Infection) AND (Cesarean section OR Obstetrics case) AND Africa (Additional file 1). These key terms were combined using Boolean operators "AND" 
and "OR" to narrow the search. A broad search was deliberately conducted to ensure all papers would be retrieved. Besides, the search was supplemented by hand searching of reference lists of key articles to retrieve additional relevant articles. The retrieved articles were exported to Endnote to screen duplicate articles. Then the two review authors assessed and reviewed independently to determine the inclusion articles.

\section{Study selection criteria Inclusion criteria}

For this meta-analysis, the following inclusion criteria were applied:

- Full text cross-sectional, cohort, randomized controlled trial study design

- Studies published after the year 2000 (to minimize the time lag bias)

- Peer-reviewed and published in the English language

- Reported the proportion of SSI and AOR (adjusted odds ratio)

- Studies conducted in Africa

\section{Exclusion criteria}

The following exclusion criteria were used in screening articles:

- Studies conducted among HIV positive patients as immunocompromised individuals are susceptible to infection

- Studies that repeated findings from the already included studies

- Studies conducted among obese women as those mothers are high risk for SSI

\section{Study selection and data extraction}

Both authors independently ran the search and screened the titles and abstracts against the inclusion/exclusion criteria. Articles satisfying the inclusion criteria were retrieved for full-text evaluation. The authors extracted the data using the pre-determined inclusion criteria. The review authors recorded the data on Microsoft excel and the extracted data included: the authors, year of publication, region, study design, sample size, the proportion of SSI, and adjusted odds ratio of rupture of membrane (Additional file 1). The study selection and data extraction were done from February 01 to March 10, 2020. Data extraction was performed independently by two review authors (AGM and YMM) to ensure accuracy and consistency of included studies (Additional file 2). To be free from other sources of bias, the two investigators assessed the risk of bias and discrepancies were solved through discussion. In addition, the authors communicated the primary authors for clarification (one author replied, but the odds of ROM was not obtained from his data). Both authors assessed the quality of the included studies using the Newcastle-Ottawa Quality Assessment Scale [18].

\section{Data analysis}

The statistical analysis was performed using STATA 11(Stata Corp. USA). Heterogeneity between-study was explored by forest plot (a visual technique that checks whether the confidence intervals of studies overlap with each other) and inconsistency index $\left(\mathrm{I}^{2}\right)$ (a statistical method which describes the percentage of total variation across studies). The $\mathrm{I}^{2}$ provides the percentage of variability due to heterogeneity rather than the chance difference or sampling error. Pooled estimates of proportion and odds ratio were calculated by a randomeffects model with a 95\% CI. The random-effects model which assesses the variability within and between studies was applied to estimate the pooled proportion of surgical site infection and to estimate odds of developing SSI among women who had ROM before delivery. The publication bias was assessed using the funnel plot (which displays effect sizes plotted against the sample size, standard error, conditional variance, or some other measure of the precision of the estimate) and Egger's test. In the presence of a cloud of data points that is symmetric around the population effect size and has the shape of a funnel, one can conclude as no publication bias [19, 20]. Sensitivity analysis, using the randomeffects model, was performed to explore the potential source of heterogeneity (or to identify the studies that affect the overall estimates of the proportion of SSI).

\section{Results}

\section{Characteristics of the included studies}

Initially, 559studies were retrieved, of which 64 were identified as being potentially eligible for this review and analysis. Finally, 15 studies (Fig. 1) comprising of 8098 women who underwent a CS were included in the pooled analysis of the proportion of SSI following CS (Fig. 2). Of 15 included articles, 11 studies were cross-sectional, 3 studies were cohort, and one article was a randomized control trial. The studies included women who gave birth through CS with a sample size ranging from 74 [21] to 1500 [12]. Among the articles included in this analysis, the least reported SSI proportion was $5 \%$ (11) and the highest proportion was $16.7 \%$ [12]. Most (10) of the studies were conducted in East Africa [4, 8, 9, 13, 22-27], two were from North Africa [11, 12] and three studies were from West Africa countries [5, 21, 28]. The quality of the studies included in this meta-analysis was accurately evaluated by using the Newcastle-Ottawa quality scale (one of the most standardized quality 


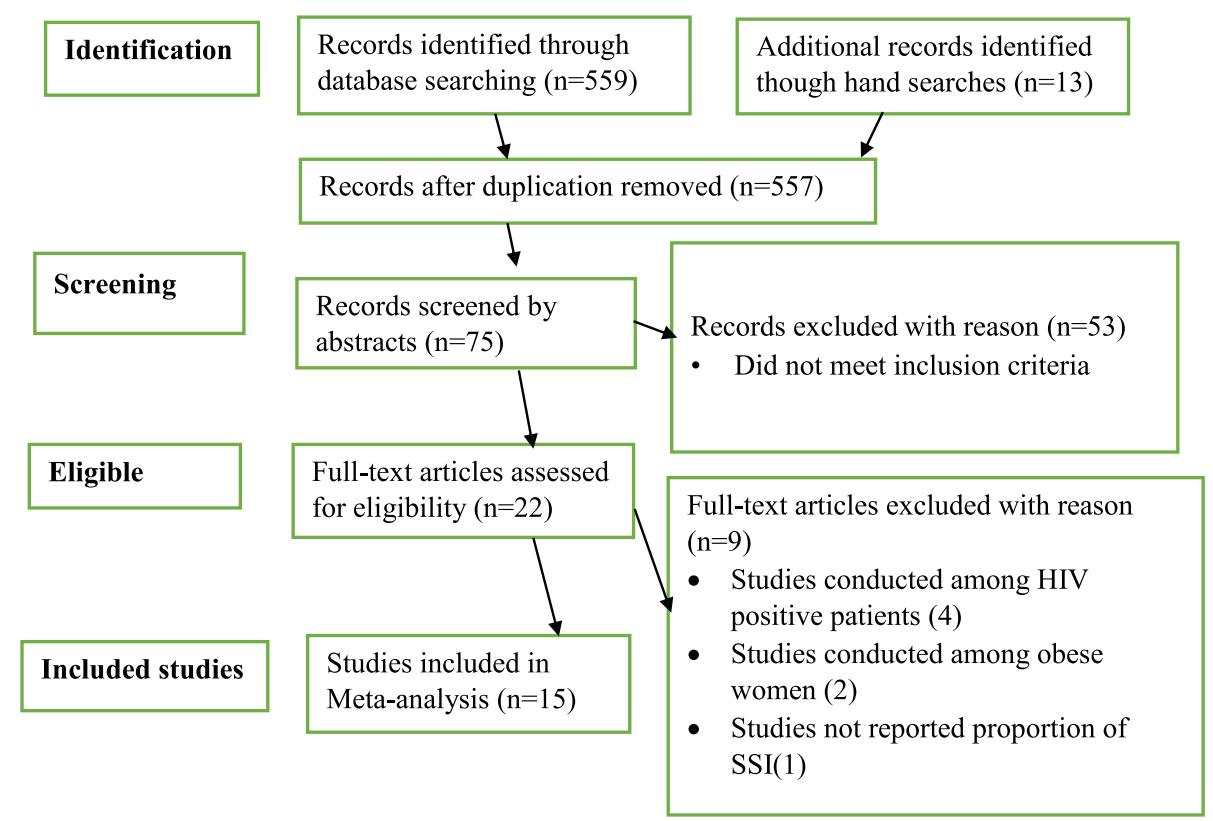

Fig. 1 PRISMA flow-diagram that depicts the phases of study selection, March 2020

\begin{tabular}{|c|c|c|c|c|}
\hline Author(year) & Country & & ES $(95 \% \mathrm{Cl})$ & $\begin{array}{l}\% \\
\text { Weight }\end{array}$ \\
\hline \multicolumn{2}{|l|}{ East Africa } & & & \\
\hline Gelaw et al [2018] & Ethipia & 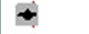 & $8.40(5.90,10.90)$ & 7.05 \\
\hline Azeze et al [2019] & Ethipia & $\star$ & $7.80(5.11,10.49)$ & 6.91 \\
\hline Molla et al [2019] & Ethipia & $\star$ & $8.10(5.17,11.03)$ & 6.72 \\
\hline Samueal et al [2017] & Ethipia & 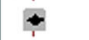 & $11.00(8.48,13.52)$ & 7.03 \\
\hline Wendmagegn et al [2018] & Ethipia & $\leftarrow$ & $11.70(7.31,16.09)$ & 5.56 \\
\hline Gelaw et al [2017] & Ethipia & + & $6.80(4.28,9.32)$ & 7.03 \\
\hline Mpogoro et al [2014] & Tanzania & 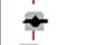 & $10.90(7.44,14.36)$ & 6.30 \\
\hline Mamo et al [2017] & Ethipia & + & $9.40(6.48,12.32)$ & 6.73 \\
\hline T Nukurinziza et al [2019] & Ruwanda & + & $10.90(8.30,13.50)$ & 6.97 \\
\hline Demsew et al [2011] & Ethipia & + & $11.40(9.16,13.64)$ & 7.23 \\
\hline \multicolumn{2}{|c|}{ Subtotal (l-squared $=37.5 \%, p=0.109$ ) } & $d$ & $9.53(8.42,10.65)$ & 67.53 \\
\hline \multirow{2}{*}{\multicolumn{5}{|c|}{ North Africa }} \\
\hline & & & & \\
\hline Abdalah et al [2018] & Egypt & $\bullet$ & $16.70(14.81,18.59)$ & 7.46 \\
\hline Morzoungui et al [2018] & Tunsia & +1 & $5.00(3.31,6.69)$ & 7.57 \\
\hline \multicolumn{2}{|c|}{ Subtotal (I-squared $=98.8 \%, p=0.000)$} & & $10.84(-0.62,22.31)$ & 15.03 \\
\hline \multicolumn{5}{|l|}{ West Africa } \\
\hline Ezechi et al [2009] & Nigeria & 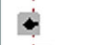 & $9.30(7.31,11.29)$ & 7.39 \\
\hline Aulakh et al [2017] & Gambia & 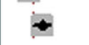 & $13.20(10.66,15.74)$ & 7.02 \\
\hline Morason-Belo et al [2009] & Nigeria & +2 & $16.20(7.81,24.59)$ & 3.03 \\
\hline \multicolumn{2}{|c|}{ Subtotal (l-squared $=72.0 \%, p=0.028$ ) } & 0 & $11.84(8.28,15.41)$ & 17.44 \\
\hline \multicolumn{2}{|c|}{ Overall (I-squared $=86.8 \%, p=0.000)$} & 0 & $10.21(8.36,12.06)$ & 100.00 \\
\hline
\end{tabular}

Fig. 2 Forest plot of pooled proportion of SSI following cesarean section from the random effects model, March 2020 


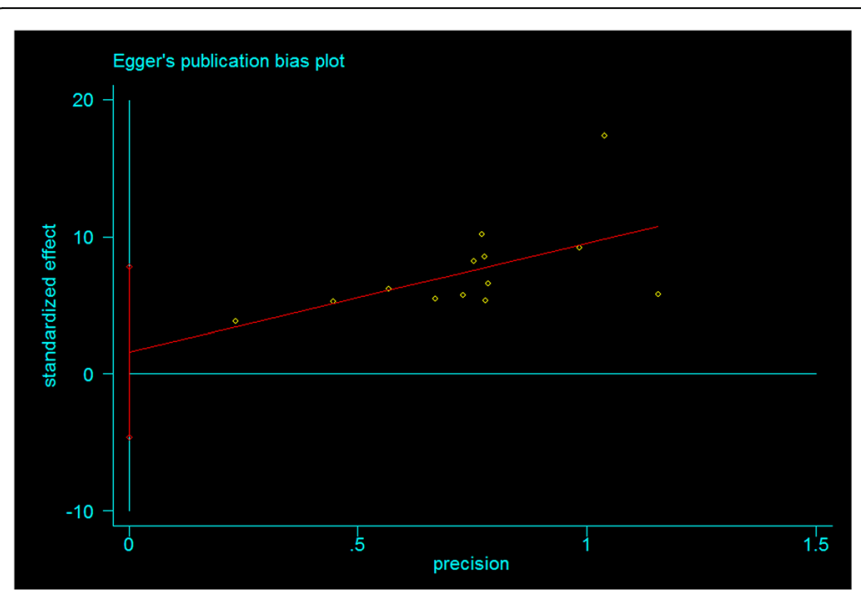

A

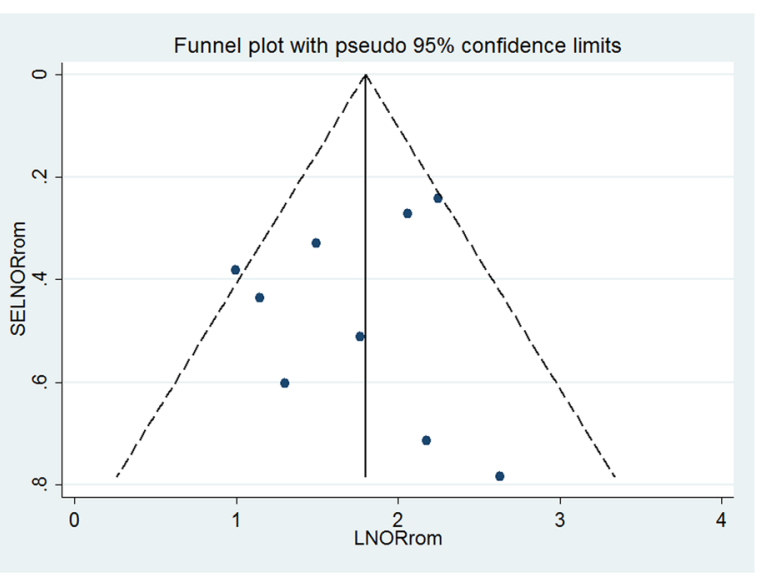

B

Fig. 3 Egger's publication bias plot (a), funnel plot showing publication bias (inverted symmetrical funnel plot) (b) among studies, March 2020

assessment tool used worldwide) [29-32]. All studies achieved a score of at least five stars, indicating good study quality of included studies.

\section{Heterogeneity and publication bias}

The included studies were assessed for heterogeneity and publication bias. Accordingly, the heterogeneity test showed a substantial heterogeneity among studies and the true variability among the 15 studies other than chance was $88.5 \%\left(\mathrm{I}^{2}=88.5 \%\right)$. To resolve the presence of heterogeneity, subgroup analysis, sensitivity analysis and random-effect model were applied (Fig. 2). The publication bias was checked by a funnel plot and Egger's test, and the plot has a symmetric inverted funnel shape showing no evidence of variability in effect sizes from studies and publication bias (Fig. 3). Egger's test also provides no evidence for small-study effects and publication bias among studies $(p=0.581)$ (Table 1) (Fig. 3).

\section{Sensitivity analysis}

A sensitivity analysis of the 15 studies was also conducted to test whether a particular study was responsible for the presence of high heterogeneity. The output showed that the estimated points of the sensitivity analysis were within the confidence interval for the pooled estimate of the meta-analysis that shows no statistical source of heterogeneity among the included studies (Fig. 4).

\section{The pooled proportion of surgical site infection}

The pooled proportion of surgical site infection is presented in a forest plot (Fig. 1). The proportion of SSI following CS in each study ranged from $5.0 \%(95 \% \mathrm{CI}=$ $3.31,6.69)$ [11] to $16.7 \%(95 \% \mathrm{CI}=14.81,18.59)$ [12]. In this meta-analysis, the overall pooled proportion of surgical site infection following CS was $10.21 \%\left(\mathrm{I}^{2}=86.8\right.$, $p<0.000 ; 95 \% \mathrm{CI}=8.36,12.06)$. In the subgroup analysis by region, the estimated proportion of SSI following CS was $9.5 \%\left(\mathrm{I}^{2}=37.5 \%, p<0.109 ; 95 \% \mathrm{CI}=7.42,10.65\right)$, $10.8 \%\left(\mathrm{I}^{2}=98.8, p<0.000 ; 95 \% \mathrm{CI}=-0.62,22.31\right)$ and $11.8 \%\left(\mathrm{I}^{2}=72.8, p<0.028 ; 95 \% \mathrm{CI}=8.28,15.41\right)$ in East, North, and West African studies, respectively (Fig. 2).

\section{The association between rupture of membrane and SSI following CS}

Nine studies were included to estimate odds of developing SSI among women who had ROM before delivery [4, 8, $12,13,22-24,27,28]$. The characteristics of the included

Table 1 Egger's test for small-study effects and publication bias among studies, March 2020

\begin{tabular}{|r|rrrrrr}
\hline \multicolumn{1}{|l}{ Egger 's test } \\
\hline std_Eff & Coef. & std. Err. & $t$ & P>|t $\mid$ & [95\% Conf. Interva1] \\
\hline slope & $\mathbf{8 . 2 1 0 3 4 8}$ & $\mathbf{3 . 3 0 9 9 7 4}$ & $\mathbf{2 . 4 8}$ & $\mathbf{0 . 0 2 8}$ & $\mathbf{1 . 0 5 9 5 8 3}$ & $\mathbf{1 5 . 3 6 1 1 1}$ \\
bias & $\mathbf{1 . 4 2 8 3 8 8}$ & $\mathbf{2 . 5 8 4 2 7 5}$ & $\mathbf{0 . 5 5}$ & $\mathbf{0 . 5 9 0}$ & $\mathbf{- 4 . 1 5 4 5 9 9}$ & $\mathbf{7 . 0 1 1 3 7 4}$ \\
\hline
\end{tabular}




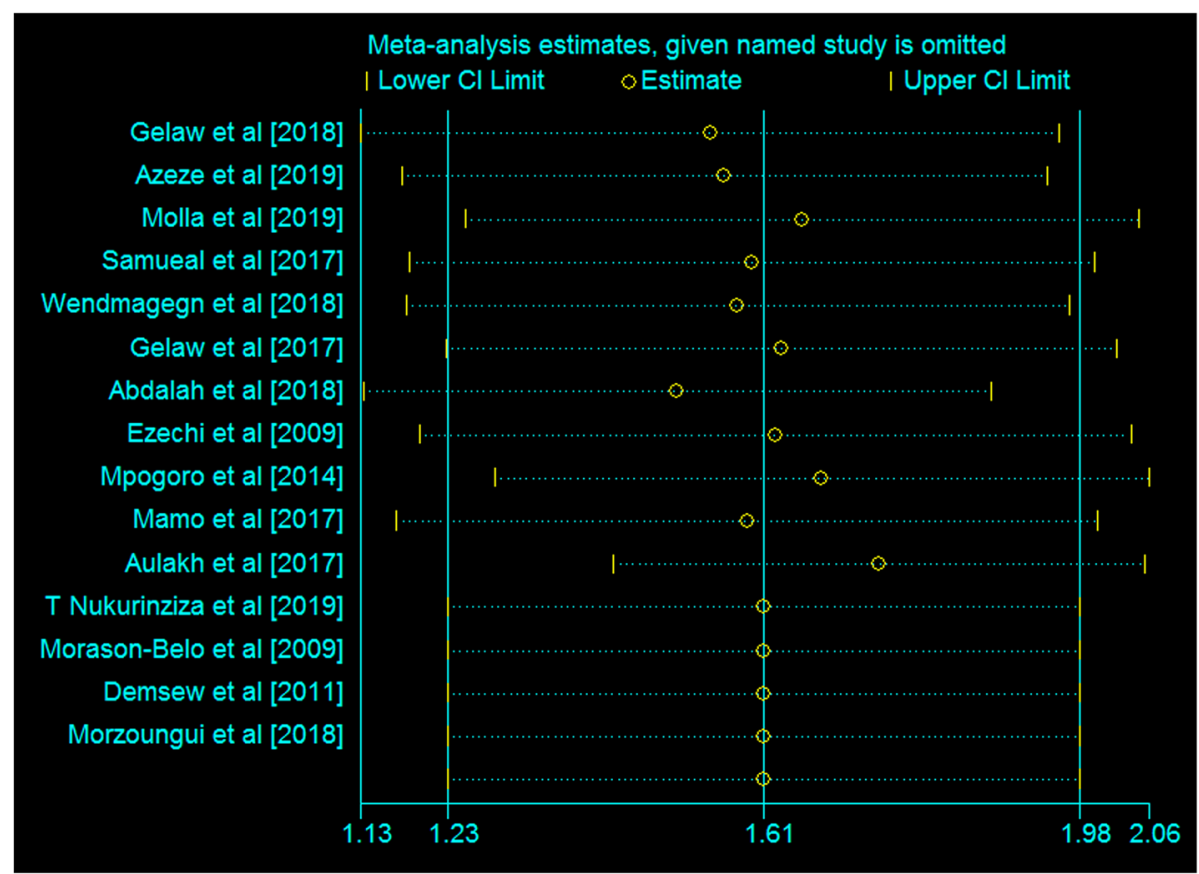

Fig. 4 A sensitivity analysis of the effect of one study on the pooled estimates, March 2020

studies are described above. The adjusted odds ratio of the articles ranged from $2.70(95 \% \mathrm{CI}=-0.62,22.31)$ [4] to $13.90(95 \% \mathrm{CI}=-0.62,22.31)$ [8]. The included studies were assessed for heterogeneity and publication bias. The analysis showed low heterogeneity among studies $\left(\mathrm{I}^{2}=\right.$ 42.7\%). The publication bias was checked by a funnel plot and Egger's test, and funnel shape showed no evidence of variability in effect sizes from studies (Fig. 3). Egger's test also showed no evidence of publication bias among studies $(p=0.514)$ (Table 2).

The pooled analysis of these 9 studies showed that the presence of an association between ROM and SSI following CS. The odds of developing SSI among women who had ROM before delivery were nearly six times higher than those who had not ROM (AOR $=5.65,95 \%$ CI: 3.95-8.07) (Fig. 5).

\section{Discussion}

This systematic review and meta-analysis, to the best of our information, is the first meta-analysis conducted in Africa to determine the pooled proportion of SSI following CS and its association with the rapture of membrane during late pregnancy. Accordingly, the overall pooled proportion of surgical site infection following CS was $10.21 \%$. Also, the subgroup analysis of this meta-analysis revealed that the proportion of surgical site infection following CS slightly varied across the regions of the included study area. The proportion of SSI following CS was higher in West Africa regions (11.84\%) than in East Africa regions (9.53\%). This pooled proportion of SSI following CS was higher than the study reported in Sub-Saharan Africa (7.3\%) [3]. A systematic review of surgical site infection by Lakhan

Table 2 Egger's test for small-study effects and publication bias among studies, March 2020

\begin{tabular}{|r|rrrrrr}
\hline \multicolumn{1}{|l}{ Egger 's test } \\
\hline std_Eff & Coef. & std. Err. & $\mathrm{t}$ & $\mathrm{P}>|\mathrm{t}|$ & [95\% Conf. Interval] \\
\hline slope & $\mathbf{1 . 9 7 6 3 1}$ & $\mathbf{. 5 6 6 9 6 2 3}$ & $\mathbf{3 . 4 9}$ & $\mathbf{0 . 0 0 7}$ & $\mathbf{. 6 9 3 7 5 2 6}$ & 3.258868 \\
bias & $-\mathbf{8 5 0 4 1 6 6}$ & $\mathbf{1 . 4 9 2 3 6 8}$ & $-\mathbf{0 . 5 7}$ & $\mathbf{0 . 5 8 3}$ & $\mathbf{- 4 . 2 2 6 3 8 8}$ & $\mathbf{2 . 5 2 5 5 5 4}$ \\
\hline
\end{tabular}




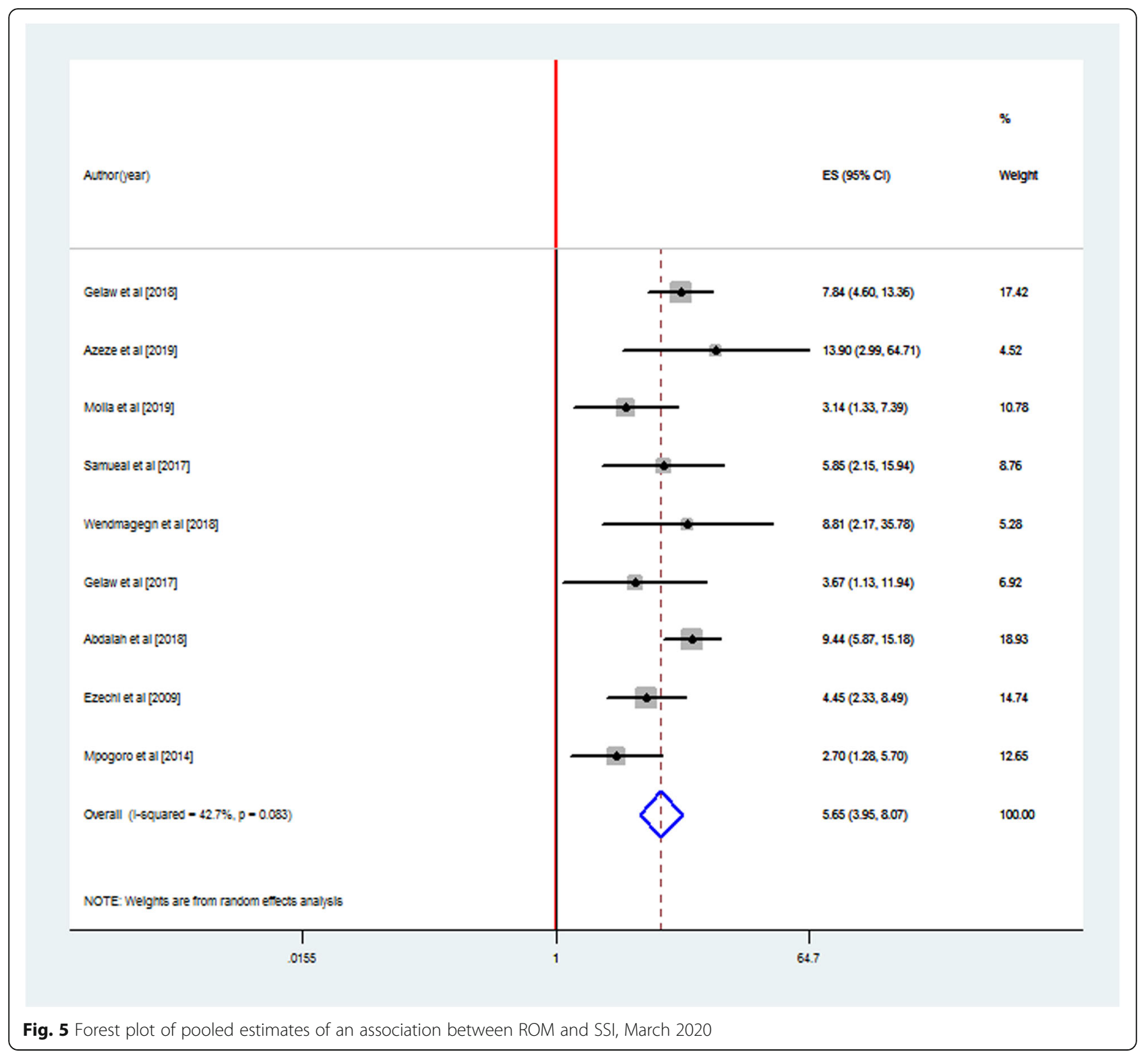

et al. reported that 1.9 to $11.2 \%$ of SSI among women operated for cesarean delivery [33]. A study from El Minya general hospital, Egypt reported a relatively higher proportion of SSI following CS (16.7\%) [12]. This high incidence of SSI following CS could be due to a continuing rise in cesarean birth rate and unsafety of perioperative surgical procedures in the health facilities during cesarean-delivery. As clearly reported in research findings, when the CS rate increases, the women at risk of developing SSI will also increase [34, 35]. Complicated pregnancies might be at higher risk for SSI following CS [35]. Lack of perioperative antibiotics and basic infrastructure might also contribute high incidence of surgical site infection following a cesarean section [35].
In this pooled meta-analysis, nine of 15 studies were included in the analysis to estimate odds of developing SSI following CS among women who had rupture of membranes before cesarean delivery. Accordingly, the odds of developing SSI among women who had ROM before cesarean delivery were nearly six times higher than those who did not have the rupture of membranes. Even though they were not reviews, this finding was supported by other studies [12, 26, 33]. This could be reasoned out that women who had ROM before cesarean delivery were more exposed to SSI. However, there had also been many conflicting studies about ROM and developing SSI following CS and the conclusiveness of this evidence might be compromised by these non-significant findings. A study published in 2006 found that there was no significant 
association between ruptured membranes before surgery and developing SSI [36]. This uniformity of the findings might arise from the inherent limitations of fragmented published articles. Even though we have pooled adjusted estimates of the association between the rupture of membrane and SSI following CS, this meta-analysis might have some limitations. The included studies were restricted in reports published in English and relevant articles available in other languages may be missed. This analysis was based only on published studies and important data might be missed from unpublished studies.

\section{Conclusions}

The proportion of surgical site infections following CS is relatively high. Women who had rupture of the membrane before delivery were more likely to develop surgical site infections following CS. Due attention should be given to the provision of prophylactic antibiotics that can reduce surgical site infection after cesarean delivery.

\section{Supplementary Information}

The online version contains supplementary material available at https://doi. org/10.1186/s40748-020-00122-2.

Additional file 1. MEDLINE via PubMed, Scopus database search for surgical site infection following cesarean section, March 2020.

Additional file 2. Summary of retrieved studies included in the analysis, March 2020.

Additional file 3. PRISMA checklist that ensure consistency and uniformity in reporting of systematic review, March 2020.

\section{Abbreviations}

AOR: Adjusted Odds Ratio; Cl: Confidence Interval; CS: Cesarean Section; $I^{2}$ : Inconsistency Index; HIV: Human Immunovirus; ROM: Rupture of Membrane; SSI: Surgical Site Infection

\section{Acknowledgements}

Not applicable.

\section{Authors' contributions}

AGM and YMM conceived and designed the study. Both authors identified the study, extract the data, analyzed and interpreted the data and wrote the manuscript. Both authors also read and approved the final version of the manuscript.

\section{Funding}

The authors did not receive any funding from any organization.

\section{Availability of data and materials}

The datasets used and/or analyzed during the current study are available from the corresponding author on reasonable request.

Ethics approval and consent to participate

Not applicable.

\section{Consent for publication}

Not applicable.

\section{Competing interests}

The authors declared that they have no competing interests.

\section{Author details}

'Department of Nursing, College of Health Science, Debre Berhan University, Po. Box. 445, Debre Berhan, Ethiopia. ²Department of Midwifery, College of Health Sciences, Debre Berhan University, Po. Box. 445, Debre Berhan, Ethiopia.

Received: 2 June 2020 Accepted: 4 December 2020

Published online: 02 January 2021

\section{References}

1. Betrán AP, Merialdi M, Lauer JA, Bing-Shun W, Thomas J, Van Look P, Wagner M. Rates of caesarean section: analysis of global, regional and national estimates. Paediatr Perinat Epidemiol. 2007;21(2):98-113.

2. Kaboré B, Soudouem G, Seck I, Millogo T, Evariste Yaméogo WM, Kouanda S. A case-control study of risk factors for surgical site infection after cesarean delivery in eastern Burkina Faso. Int J Gynecol Obstet. 2016;135(S1): S107-10.

3. Chu K, Maine R, Trelles M. Cesarean section surgical site infections in subSaharan Africa: a multi-country study from Medecins sans Frontieres. World J Surg. 2015:39(2):350-5.

4. Mpogoro FJ, Mshana SE, Mirambo MM, Kidenya BR, Gumodoka B, Imirzalioglu C. Incidence and predictors of surgical site infections following caesarean sections at Bugando medical Centre, Mwanza, Tanzania. Antimicrob Resist Infect Control. 2014:3(1):25.

5. Aulakh A, Idoko P, Anderson ST, Graham W. Caesarean section wound infections and antibiotic use: a retrospective case-series in a tertiary referral hospital in the Gambia. Trop Dr. 2018;48(3):192-9.

6. De Lissovoy G, Fraeman K, Hutchins V, Murphy D, Song D, Vaughn BB. Surgical site infection: incidence and impact on hospital utilization and treatment costs. Am J Infect Control. 2009;37(5):387-97.

7. De Nardo P, Gentilotti E, Nguhuni B, Vairo F, Chaula Z, Nicastri E, Nassoro MM, Bevilacqua N, Ismail A, Savoldi A, Zumla A. Post-caesarean section surgical site infections at a Tanzanian tertiary hospital: a prospective observational study. J Hosp Infect. 2016;93(4):355-9.

8. Azeze GG, Bizuneh AD. Surgical site infection and its associated factors following cesarean section in Ethiopia: a cross-sectional study. BMC Res Notes. 2019;12(1):288.

9. Amenu D, Belachew T, Araya F. Surgical site infection rate and risk factors among obstetric cases of Jimma University specialized hospital, Southwest Ethiopia. Ethiop J Health Sci. 2011;21(2):91-100.

10. Saeed KBM, Greene RA, Corcoran P, et al. Incidence of surgical site infection following caesarean section: a systematic review and meta-analysis protocol. BMJ Open. 2017;7:e013037. https://doi.org/10.1136/bmjopen-2016-013037.

11. Merzougui $L$, Marwen $N$, Hannachi $H$, Asma M, Elhaj OB, Waddah M, Fatnassi $R$. Incidence et facteurs de risque de l'infection du site opératoire après césarienne dans une maternité de Tunisie. Sante Publique. 2018;30(3):339-47.

12. Abdallah A, Sayed Rafeek ME. Risk factors of surgical site infection of cesarean section and role of skin cleansing and prophylactic antibiotic. Int J Reprod Med Gynecol. 2018;4(2):047-51.

13. Wodajo S, Belayneh M, Gebremedhin S. Magnitude and factors associated with post-cesarean surgical site infection at Hawassa University teaching and referral hospital, southern Ethiopia: a cross-sectional study. Ethiop J Health Sci. 2017:27(3):283-90.

14. Laloto TL, Gemeda DH, Abdella SH. Incidence and predictors of surgical site infection in Ethiopia: prospective cohort. BMC Infect Dis. 2017:17(1):119.

15. World Health Organization. WHO guidelines for safe surgery 2009: safe surgery saves lives. Geneva: World Health Organization; 2009. Available from: https://apps.who.int/iris/bitstream/10665/44185/1/9789241598552_ eng.pdf.

16. Ercole FF, Starling CE, Chianca TC, Carneiro M. Applicability of the national nosocomial infections surveillance system risk index for the prediction of surgical site infections: a review. Braz J Infect Dis. 2007;11(1):134-41.

17. Stroup DF, Berlin JA, Morton SC, Olkin I, Williamson GD, Rennie D, Moher D, Becker BJ, Sipe TA, Thacker SB. Meta-analysis of observational studies in epidemiology: a proposal for reporting. JAMA. 2000;283(15):2008-12.

18. Wells GA, Shea B, O'Connell D, Peterson J, Welch V, Losos M, et al. Newcastle-Ottawa Quality Assessment Scale - Case-Control Studies. Canada: University of Ottawa; 2017

19. Haidich AB. Meta-analysis in medical research. Hippokratia. 2010;14(Suppl 1):29.

20. Field AP, Gillett R. How to do a meta-analysis. Br J Math Stat Psychol. 2010; 63(3):665-94. 
21. Morhason-Bello IO, Oladokun A, Adedokun BO, Obisesan KA, Ojengbede $\mathrm{OA}$, Okuyemi OO. Determination of post-caesarean wound infection at the University college hospital Ibadan Nigeria. Niger J Clin Pract. 2009;12(1):1-5.

22. Gelaw KA, Aweke AM, Astawesegn FH, Demissie BW, Zeleke LB. Surgical site infection and its associated factors following cesarean section: a cross sectional study from a public hospital in Ethiopia. Patient Saf Surg. 2017;11(1):18.

23. Molla M, Temesgen K, Seyoum T, Melkamu M. Surgical site infection and associated factors among women underwent cesarean delivery in Debretabor general hospital, Northwest Ethiopia: hospital based cross sectional study. BMC Pregnancy Childbirth. 2019;19(1):317.

24. Gelaw MW, Abdela A. Prevalence of surgical site infection and associated factors among mothers after cesarean delivery in zewditu memorial hospital. Ethiopian J Reprod Health. 2018;10:4.

25. Nkurunziza T, Kateera F, Sonderman K, Gruendl M, Nihiwacu E, Ramadhan B, Cherian T, Nahimana E, Ntakiyiruta G, Habiyakare C, Ngamije P. Prevalence and predictors of surgical-site infection after caesarean section at a rural district hospital in Rwanda. Br J Surg. 2019;106(2):e121-8.

26. Mamo T, Abebe TW, Chichiabellu TY, Anjulo AA. Risk factors for surgical site infections in obstetrics: a retrospective study in an Ethiopian referral hospital. Patient Saf Surg. 2017;11(1):24.

27. Wendmagegn TA, Abera GB, Tsehaye WT, Gebresslasie KB, Tella BG. Magnitude and determinants of surgical site infecion among women underwent cesarean section in Ayder comprehensive specialized hospital Mekelle City, Tigray region, northern Ethiopia, 2016. BMC Pregnancy Childbirth. 2018;18(1):489.

28. Ezechi OC, Edet A, Akinlade H, Gab-Okafor CV, Herbertson E. Incidence and risk factors for caesarean wound infection in Lagos Nigeria. BMC Res Notes. 2009;2(1):186.

29. Luchini C, Stubbs B, Solmi M, Veronese N. Assessing the quality of studies in meta-analyses: advantages and limitations of the Newcastle Ottawa scale. World J Meta Analysis. 2017;5(4):80-123.

30. Munn Z, Moola S, Lisy K, Riitano D, Tufanaru C. Methodological guidance for systematic reviews of observational epidemiological studies reporting prevalence and cumulative incidence data. Int J Evid Based Healthc. 2015; 13(3):147-53.

31. Moola S, Munn Z, Tufanaru C, Aromataris E, Sears K, Sfetcu R, Currie M, Qureshi R, Mattis P, Lisy K, Mu PF. Chapter 7: Systematic reviews of etiology and risk. In: Aromataris E, Munn Z (Editors). JBI Manual for Evidence Synthesis. JBI, 2020. Available from https://synthesismanual.jbi.global.https:// doi.org/10.46658/JBIMES-20-08

32. Tufanaru C, Munn Z, Aromataris E, Campbell J, Hopp L. Chapter 3 : Systematic reviews of effectiveness. In: Aromataris E, Munn Z, editors. Joanna Briggs Institute Reviewer's Manual: The Joanna Briggs Institute; 2017. Available from https://reviewersmanual.

33. Lakhan P, Doherty J, Jones M, Clements A. A systematic review of maternal intrinsic risk factors associated with surgical site infection following caesarean sections. Healthc Infect. 2010;15(2):35-41.

34. Sway A, Nthumba P, Solomkin J, Tarchini G, Gibbs R, Ren Y, Wanyoro A. Burden of surgical site infection following cesarean section in sub-Saharan Africa: a narrative review. Int J Womens Health. 2019;1:309-18.

35. Mackeen AD, Packard RE, Ota E, Berghella V, Baxter JK. Timing of intravenous prophylactic antibiotics for preventing postpartum infectious morbidity in women undergoing cesarean delivery. Cochrane Database Syst Rev. 2014(12):11-7. https://doi.org/10.1002/14651858.CD009516.pub2.

36. Johnson A, Young D, Reilly JV. Caesarean section surgical site infection surveillance. J Hosp Infect. 2006:64(1):30-5.

\section{Publisher's Note}

Springer Nature remains neutral with regard to jurisdictional claims in published maps and institutional affiliations.

Ready to submit your research? Choose BMC and benefit from:

- fast, convenient online submission

- thorough peer review by experienced researchers in your field

- rapid publication on acceptance

- support for research data, including large and complex data types

- gold Open Access which fosters wider collaboration and increased citations

- maximum visibility for your research: over $100 \mathrm{M}$ website views per year

At $\mathrm{BMC}$, research is always in progress.

Learn more biomedcentral.com/submissions 